\title{
Size-resolved exposure risk of persistent free radicals (PFRs) in atmospheric aerosols and their potential sources
}

\author{
Qingcai Chen ${ }^{1}$, Haoyao Sun ${ }^{1}$, Wenhuai Song ${ }^{2}$, Fang $\mathrm{Cao}^{2}$, Chongguo Tian $^{3}$, and Yan-Lin Zhang ${ }^{2}$ \\ ${ }^{1}$ School of Environmental Science and Engineering, Shaanxi University of Science and Technology, Xi'an 710021, China \\ ${ }^{2}$ Yale - NUIST Center on Atmospheric Environment, International Joint Laboratory on Climate and Environment Change \\ (ILCEC), Nanjing University of Information Science and Technology, Nanjing 210044, China \\ ${ }^{3}$ Key Laboratory of Coastal Environmental Processes and Ecological Remediation, Yantai Institute of Coastal Zone Research, \\ Chinese Academy of Sciences, Yantai 264003, China
}

Correspondence: Yan-Lin Zhang (dryanlinzhang@outlook.com, zhangyanlin@nuist.edu.cn)

Received: 16 February 2020 - Discussion started: 1 April 2020

Revised: 14 September 2020 - Accepted: 23 September 2020 - Published: 27 November 2020

\begin{abstract}
Environmentally persistent free radicals (EPFRs) are a new type of substance with potential health risks. EPFRs are widely present in atmospheric particulates, but there is a limited understanding of the size-resolved health risks of these radicals. This study reports the exposure risks and source of EPFRs in atmospheric particulate matter (PM) of different particle sizes $(<10 \mu \mathrm{m})$ in Linfen, a typical coalburning city in China. The type of EPFRs in fine particles $(<2.1 \mu \mathrm{m})$ is different from that in coarse particles $(2.1-$ $10 \mu \mathrm{m})$ in both winter and summer. However, the EPFR concentration is higher in coarse particles than in fine particles in summer, and the opposite trend is found in winter. In both seasons, combustion sources are the main sources of EPFRs, with coal combustion as the major contributor in winter, while other fuels are the major source in summer. Dust contributes part of the EPFRs, and it is mainly present in coarse particles in winter and the opposite in summer. The upper respiratory tract was found to be the area with the highest risk of exposure to EPFRs of the studied aerosols, with an exposure equivalent to that of approximately 21 cigarettes per person per day. Alveolar exposure to EPFRs is equivalent to 8 cigarettes per person per day, with combustion sources contributing the most to EPFRs in the alveoli. This study helps us to better understand the potential health risks of atmospheric PM with different particle sizes.
\end{abstract}

\section{Introduction}

Free radicals are atoms or groups containing unpaired electrons, such as hydroxyl radicals and superoxide radicals, and they usually have strong chemical reactivity and short lifetimes (Pryor et al., 1986; Finkelstein, 1982). Free radicals with long lifetimes (months or even years) in the environment are currently called environmentally persistent free radicals (EPFRs), which have received much attention in recent years as new environmentally hazardous substances (Vejerano et al., 2018; Gehling and Dellinger, 2013; Chen et al., 2019c). EPFRs can be used as an active intermediate to catalyze the production of reactive oxygen species (ROS) by oxygen molecules, thus endangering human health (D'Arienzo et al., 2017; Thevenot et al., 2013; Harmon et al., 2018; Blakley et al., 2001; Khachatryan and Dellinger, 2011). Studies have found that EPFRs are present in different environmental media, such as water and soil, and even in the atmosphere (Dellinger et al., 2001; Truong et al., 2010; Vejerano et al., 2012a).

A number of studies have investigated the occurrences, sources and formation process of EPFRs in atmospheric particulates in different regions. For example, in the studies of Rostock in Germany, Taif in Saudi Arabia and Xuanwei in China, the average concentration of EPFRs in atmospheric particulate matter (PM) was reported to be in the range of $\sim 10^{16}-10^{18}$ spins g $^{-1}$ (Wang et al., 2019; Arangio et al., 2016; Shaltout et al., 2015). Atmospheric EPFRs are mainly carbon-centered radicals with adjacent oxygen 
atoms (Gehling and Dellinger, 2013). EPFRs of different lifetimes are present in atmospheric PM, with only a few hours for short-lifetime EPFRs and several years for longlifetime EPFRs that show no signs of decay (Gehling and Dellinger, 2013; Chen et al., 2019c). Most studies indicate that sources of transportation and combustion may be the primary EPFR sources in atmospheric PM (Wang et al., 2018; Yang et al., 2017; Chen et al., 2019b). Chen et al. (2018b, $2019 \mathrm{~b}$ ) found that strong atmospheric photochemical effects in summer and dust particles may also be important sources of EPFRs. The process of electron transfer and stabilization between the surface of metal oxides (such as iron, copper, zinc and nickel) and substituted aromatic molecules under high temperatures is considered to be the main process for the formation of EPFRs in atmospheric particles (Truong, 2010; Vejerano et al., 2012a; Patterson et al., 2013; Vejerano et al., 2011, 2012b). However, the study by Chen et al. (2018a) suggests that EPFRs in atmospheric particulates are mainly derived from graphite oxide-like substances produced during combustion. In addition to primary sources such as combustion, secondary chemical processes in the atmosphere may also be an important source of EPFRs in atmospheric PM (Chen et al., 2019b, d; Tong et al., 2018).

Different particle sizes of atmospheric PM pose different health risks to humans, depending on the deposition efficiency of the particles and the chemical composition and concentrations of hazardous substances they contain (Strak et al., 2012; Valavanidis et al., 2008). Among various hazardous substances, EPFRs may also be involved in the toxicity of atmospheric particulates. Yang et al. (2017) studied the EPFRs that are extractable by dichloromethane in different particle sizes in Beijing in winter and found that the concentration of EPFRs was the highest in particles with sizes $<1 \mu \mathrm{m}$. Arangio et al. (2016) found that the concentration of EPFRs in $180 \mathrm{~nm}$ particles was the highest in the $56 \mathrm{~nm}-1.8 \mu \mathrm{m}$ particle size range. Although several studies have examined the particle size distribution of EPFRs, systematic studies have not been conducted on the formation process, source and exposure assessment of EPFRs in atmospheric particles with different particle sizes.

This study takes Linfen as an example. Linfen is one of the cities in China with the most serious air pollution and is a typical coal-burning city. The particle size distribution of EPFRs in atmospheric PM in this region was studied using electron paramagnetic resonance (EPR) spectroscopy. The effects of particle size and season on the source, formation process and health risk of EPFRs were revealed. In particular, the comprehensive health risks of EPFRs were evaluated, and it was found that the upper respiratory tract is the area with the highest risk of EPFRs' exposure, which is equivalent to 21 cigarettes per person per day. This study is of great significance for understanding the source and formation process of EPFRs in atmospheric particulates as well as for health risk assessments.

\section{Experimental section}

\subsection{Sample collection}

The sampling site for this study is located in Hongdong $\left(36^{\circ} 23^{\prime}, 111^{\circ} 40^{\prime} \mathrm{E}\right)$ in Shanxi, China. To collect atmospheric particles of different sizes $(0-10 \mu \mathrm{m})$, this study used a Thermo Anderson Mark II sampler to collect aerosol samples of nine sizes. The samples were collected on a prebaked quartz filter $\left(450^{\circ} \mathrm{C}, 4.5 \mathrm{~h}\right)$, and the sampling dates were as follows: in winter, 26 January to 4 February $2017, n=10$; and in summer, 31 July to 24 August 2017, $n=12$. The samples were placed in a $-20^{\circ} \mathrm{C}$ refrigerator prior to analysis.

\subsection{EPFR analysis}

The EPR spectrometer (MS5000, Freiberg, Germany) is used to detect EPFRs in atmospheric samples. The filters were cut into thin strips $(5 \mathrm{~mm} \times 28 \mathrm{~mm})$ and put it into the sample tank of the quartz tissue cell (the size of the sample tank is $10 \mathrm{~mm} \times 30 \mathrm{~mm}$ ). Then the quartz tissue cell with attached filter sample was placed in a resonant cavity and analyzed by an EPR spectrometer. The detection parameters were magnetic field strength, 335-342 mT; detection time, $60 \mathrm{~s}$; modulation amplitude, $0.20 \mathrm{mT}$; number of detections, 1 ; and microwave intensity, $8.0 \mathrm{~mW}$. Specific testing protocols have been described previously (Chen et al., 2018c).

\subsection{Carbon composition analysis}

The contents of organic carbon (OC) and elemental carbon (EC) in the filter samples were analyzed using a semicontinuous OC/EC analyzer (Model 4, Sunset Lab. Inc., Oregon, USA) with a NIOSH 5040 detection protocol (Lin et al., 2009).

The water-soluble organic carbon (WSOC) concentration was analyzed using an automatic TOC-LCPH analyzer (Shimadzu, Japan). The WSOC extraction was performed with ultrapure water under ultrasonication for $15 \mathrm{~min}$, and all WSOC concentrations were blank-corrected. The concentration of OC in the MSM (methanol-soluble materials) was calculated as the difference between the OC and WSOC (watersoluble organic carbon) concentrations. This calculation assumes that all water-insoluble organic carbon (WISOC) in the aerosol can be extracted with $\mathrm{MeOH}$, and the rationality of this assumption has been verified elsewhere (Mihara and Michihiro, 2013; Liu et al., 2013; Cheng et al., 2016; Chen et al., 2019a).

\subsection{PAH analysis}

PAHs were detected using gas chromatography-mass spectrometry (GC-MS) on a GC7890B/MS5977A (Agilent Technologies, Clara, CA). Quartz-fiber filter samples $(8 \mathrm{~mm}$ in diameter) were cut from each $25 \mathrm{~mm}$ quartz-fiber filter substrate used on the ELPI impactor stages using a stainless- 
steel round punch over a clean glass dish and loaded into the TD glass tube. Next, the TD glass tube was heated to $310^{\circ} \mathrm{C}$ at a rate of $12^{\circ} \mathrm{C} \mathrm{min}^{-1}$ and thermally desorbed at $310^{\circ} \mathrm{C}$ for $3 \mathrm{~min}$. The desorbed organic compounds were trapped on the head of a GC column (DB-5MS: 5\% diphenyl-95\% dimethyl siloxane copolymer stationary phase, $0.25 \mathrm{~mm}$ i.d., $30 \mathrm{~m}$ length and $0.25 \mathrm{~mm}$ thickness). A total of 16 target PAHs were identified based on retention time and typical ion fragments of each PAH standard, including 16 EPA parent PAHs (p-PAHs). The method detection limits (MDLs) ranged from $0.2 \mathrm{pg} \mathrm{mm}^{-2}$ (Ace) to $0.6 \mathrm{pg} \mathrm{mm}^{-2}$ (Incdp). Naphthalene-D8, acenaphthene-D10, phenanthreneD10, chrysene-D12 and perylene-D12 were used for the analytical recovery check. All compounds were recovered with a desorption recovery percentage of $>90 \%$. Specific testing protocols have been described previously (Han et al., 2018; Song et al., 2020).

\subsection{Metal element analysis}

The concentration of metal elements in the samples was determined by a Thermo X2 series inductively coupled plasma mass spectrometer (ICP-MS, Thermo, USA). The metal elements analyzed in summer were $\mathrm{Na}, \mathrm{Mg}, \mathrm{K}, \mathrm{Ca}, \mathrm{Ti}, \mathrm{V}, \mathrm{Cr}$, $\mathrm{Mn}, \mathrm{Fe}, \mathrm{Co}, \mathrm{Ni}, \mathrm{Cu}, \mathrm{Zn}, \mathrm{As}, \mathrm{Cd}, \mathrm{Pb}$ and $\mathrm{Al}$, and those in winter were $\mathrm{Al}, \mathrm{Zn}, \mathrm{V}, \mathrm{Cr}, \mathrm{Mn}, \mathrm{Co}, \mathrm{Ni}, \mathrm{Cu}, \mathrm{As}, \mathrm{Se}, \mathrm{Sr}, \mathrm{Cd}, \mathrm{Ba}$ and $\mathrm{Pb}$. The specific measurement method is based on the study of Qi et al. (2016).

\subsection{Data statistics method}

The source and formation process of EPFRs in PM with different particle sizes were analyzed by nonnegative matrix factorization (NMF). The method is based on the study of Chen et al. (2016, 2019e). Briefly, NMF analysis of EPFR data, metal element contents, OC/EC contents and PAH contents was performed in MATLAB. The version of the NMF toolbox is 1.4 (https://sites.google.com/site/nmftool/, last access: 10 November 2017). A gradient-based multiplication algorithm was used to find a solution from multiple random starting values, and then the first algorithm was used to find the final solution based on the least-squares effective-set algorithm. To find a global solution, the model was run 100 times, each time with a different initial value. By comparing the 1-12=factor model (Fig. S4) with the residual of the spectral load, the 6-factor (summer) and 10-factor (winter) NMF models were finally selected.

\subsection{EPFR exposure evaluation}

To assess the health risks of EPFRs, this study divided the respiratory system into three parts based on the human breathing model: extrathoracic (ET) areas, including the anterior nasal cavity, posterior nasal cavity, oral cavity and throat; tracheobronchial (TB) areas, including the trachea, bronchi, bronchioles and terminal bronchi; and pulmonary
(P) areas, including the alveolar ducts and alveoli. Then, the sedimentation rates of different particle sizes in different areas of the respiratory system were determined to calculate the exposure risk of EPFRs. Here, the human respiratory system particulate deposition model of Salma et al. (2002) was used, and the specific data can be found in Tables S3 and S4 in the Supplement.

In addition, the daily inhaled concentration of EPFRs into the concentration of free radicals in cigarettes was converted. The specific conversion method is as follows:

$N_{\text {cig }}=\left(C_{\text {EPFRs }} \cdot V\right) /\left(\mathrm{RC}_{\text {cig }} \cdot C_{\text {tar }}\right)$,

where $N_{\text {cig }}$ represents the number of cigarettes (per person per day), $C_{\text {EPFRs }}$ (spins $\mathrm{m}^{-3}$ ) represents the atmospheric concentration of EPFRs in PM and $V$ represents the amount of air inhaled by an adult per day $\left(20 \mathrm{~m}^{3} \mathrm{~d}^{-1}\right)$ (Environmental Protection Agency, 1988). $\mathrm{RC}_{\text {cig }}\left(4.75 \times 10^{16}\right.$ spins g $\left.^{-1}\right)$ (Baum et al., 2003; Blakley et al., 2001; Pryor et al., 1983; Valavanidis and Haralambous, 2001) indicates the concentration of free radicals in cigarette tar, and $C_{\mathrm{tar}}(0.013 \mathrm{~g}$ per cigarette) indicates the amount of tar per cigarette (Gehling and Dellinger, 2013).

\section{Results and discussion}

\subsection{Concentrations and types of EPFRs}

Figure 1a shows the concentration distribution of EPFRs with different particle sizes in different seasons. EPFRs were detected in the particles of each tested size (the EPR spectrum is shown in Fig. S1 in the Supplement), but their EPFR concentration levels were different. In summer, the concentration of EPFRs in fine particles (particle size < $2.1 \mu \mathrm{m})$ is $(3.2-8.1) \times 10^{13}$ spins $\mathrm{m}^{-3}$, while the concentration of EPFRs in coarse particles (particle size $>2.1 \mu \mathrm{m}$ ) is 1-2 orders of magnitude higher than that of fine particles, reaching values of $(2.2-3.5) \times 10^{14}$ spins $\mathrm{m}^{-3}$. Winter samples show completely different characteristics from summer samples. The concentration of EPFRs in fine particles

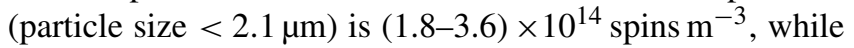
the concentration of EPFRs in coarse particles (particle size $>2.1 \mu \mathrm{m}$ ) is smaller than that of fine particles, with values of $(1.0-2.1) \times 10^{14}$ spins $\mathrm{m}^{-3}$. In addition, the concentration of EPFRs in particulates $<0.43 \mu \mathrm{m}$ in winter is very high, but it is very low in summer. According to the results of factor analysis in Sect. 3.2 of this study, this particulate matter is related to combustion, which indicates that coal combustion in winter may provide an important contribution to EPFRs. The EPFR concentration in the fine PM of Linfen reported above is equivalent to that in the fine PM of Xi'an, but it is 10 times smaller than that in the fine PM of Beijing (Yang et al., 2017; Chen et al., 2019b). Although the particle size distribution characteristics of EPFRs in winter and summer are different, their concentration levels are similar, which in- 

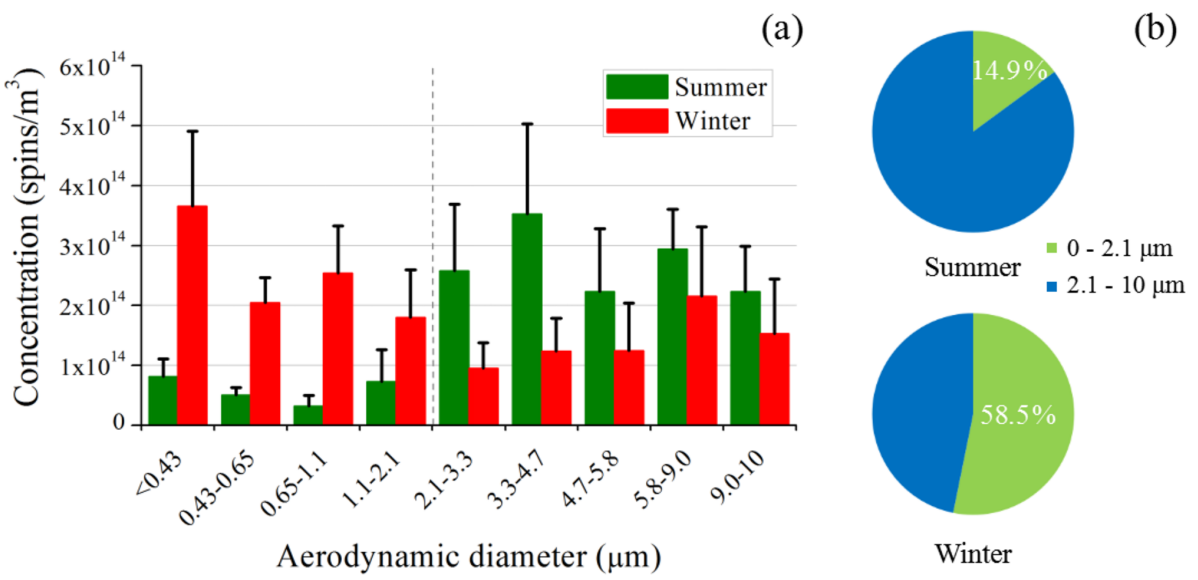

Figure 1. The concentration of EPFRs in PM with different particle sizes. (a) Atmospheric concentrations of EPFRs in different particle sizes in summer and winter. (b) The relative contribution of fine particles and coarse particles to the total EPFR concentration.

dicates that the EPFR concentration is not related to the PM concentration but is determined by the source characteristics. The source characteristics will be discussed in detail in the factor analysis section.

Figure $1 \mathrm{~b}$ shows the concentration ratio of EPFRs in coarse and fine particles. The contribution of EPFRs in fine PM in summer is only $14.9 \%$, while in winter it is $58.5 \%$. The differences in EPFR concentrations with particle size may be related to the source of EPFRs. For example, coarse particles are often associated with dust sources and biogenic aerosols. In another study, the results have shown that dust particles contain large amounts of metallic EPFRs and that they can be transported over long distances (Chen et al., 2018b). EPFRs in fine particles may be mainly derived from the combustion process, such as traffic sources, which are considered to be an important source of EPFRs in atmospheric PM (Chen et al., 2019b). Due to winter heating in the Linfen area, the amount of coal burning increases sharply in this season. In 2017, the nonclean heating (coalfired heating) rate of urban heating energy structures in Linfen was $40 \%$ (data source: http://www.linfen.gov.cn/, last access: 28 May 2019). With the burning of coal, large amounts of EPFRs are produced, and in the summer, EPFRs emitted by burning coal should be much less than those emitted in winter. This can explain to a certain extent that the contribution of fine particles to summer EPFRs is small, and the contribution of winter EPFRs is very large.

The $g$ factor obtained by using EPR to analyze the sample is an important parameter to distinguish the type of EPFR. It is the ratio of the electronic magnetic moment to its angular momentum (Shaltout et al., 2015; Arangio et al., 2016). The $g$ factor of carbon-centered persistent free radicals is generally less than 2.003, the $g$ factor of oxygen-centered persistent radicals is generally greater than 2.004 and the $g$ factor of carbon-centered radicals with adjacent oxygen atoms is between 2.003 and 2.004 (Cruz et al., 2012). Figure 2a shows the $g$ factor distribution characteristics of EPFRs in different particle sizes in summer and winter. The $g$ factor of fine particles and coarse particles shows different characteristics. The $g$ factor of EPFRs in fine particles (particle size $<2.1 \mu \mathrm{m}$ ) ranges from 2.0034 to 2.0037, which may be from carboncentered radicals with adjacent oxygen atoms. However, the $g$ factor of EPFRs in coarse particles (particle size $>2.1 \mu \mathrm{m}$ ) is significantly less than that of fine particles. The $g$ factor ranges from 2.0031 to 2.0033, indicating that EPFRs in coarse particles are more carbon-centered than those in fine particles and are free of heteroatoms. As shown in Fig. 2b, the $g$ factor varied differently depending on season. The $g$ factor of summer PM showed a significant decreasing trend with increasing concentration, while the $g$ factor of winter PM showed a significant increasing trend with increasing EPFR concentration. Oyana et al. (2017) studied EPFRs in the surface dust of leaves in the Memphis region of the United States and found that the concentration of EPFRs was positively correlated with the $g$ factor, and they believed that this was related to the source of EPFRs. This phenomenon indicates that the sources and toxicity of EPFRs in winter and summer are different.

\subsection{Factor analysis of EPFRs}

To explore the possible sources and formation process of EPFRs in atmospheric particles with different particle sizes, the NMF model was used to statistically analyze EPFRs, carbon components, PAHs and metal elements in samples. The factors obtained by the NMF model should reflect the different sources and generation process of EPFRs. As shown in Fig. 3a1 and b1, the three main contributing factors to EPFRs in summer and winter are shown (see Figs. S5, S6 for spectra of other factors), which explain $94.5 \%$ and $83.8 \%$ of the EPFR concentrations in summer and winter, respectively.

As shown in Fig. 3a1, the typical spectral characteristic of summer factor 1 is that it contains a small fraction of EC 

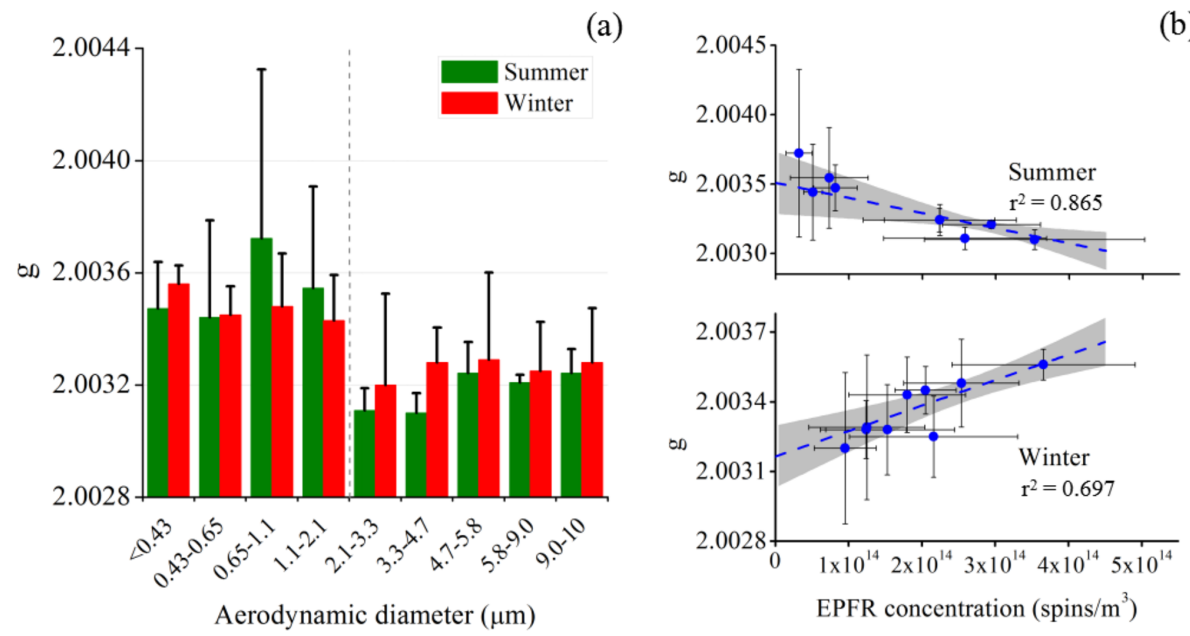

Figure 2. A $g$ factor comparison. (a) Comparison of $g$ factors of EPFRs in different particle sizes in different seasons. (b) Correlation analysis of $g$ factors and concentrations of EPFRs in summer and winter PM. The gray areas in the figure represent $95 \%$ confidence intervals.

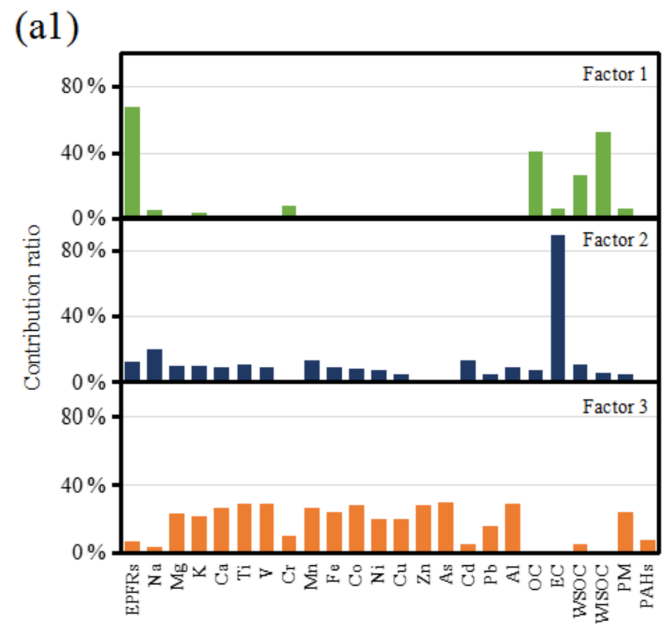

(a2)

(b1)
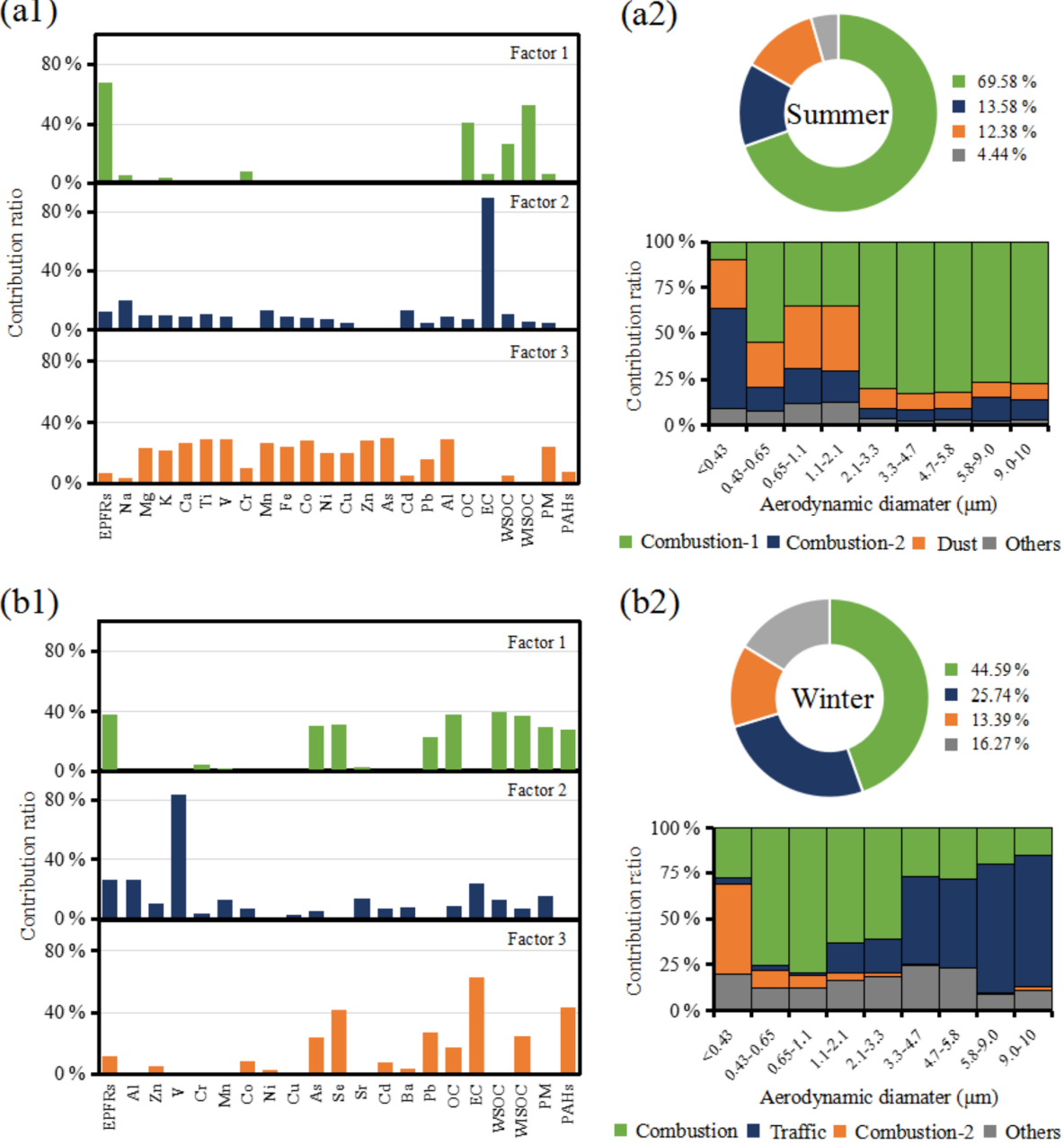

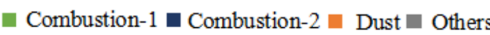

(b2)
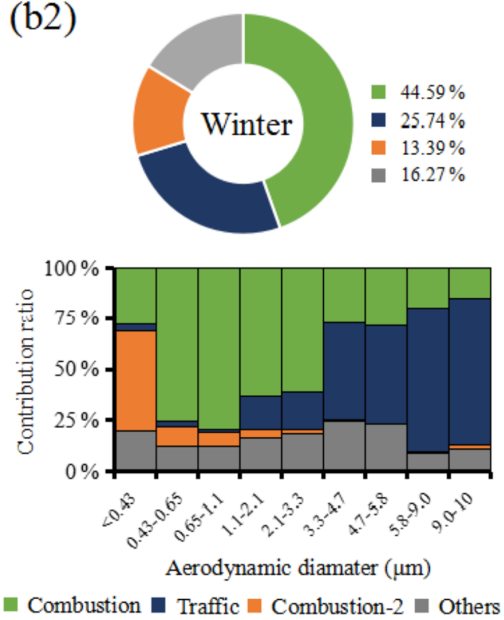

Figure 3. Factor analysis of EPFRs in different particle sizes in different seasons. Panels (a1) and (b1) represent the results of factor analysis for summer and winter, respectively. Panels (a2) and (b2) represent the contribution of various factors in summer and winter, respectively, to EPFRs and the relative contributions of each factor for different particle sizes. 
components and a large amount of OC components, which indicates that combustion may be the source associated with this factor. This factor has the highest loading of OC, especially WISOC; this fraction mainly contains macromolecular organic substances, which are considered to contribute to the main atmospheric particulate EPFRs and to be graphite oxide-like substances (Q. Chen et al., 2017, 2018a). Factor 2 is different from factor 1 ; factor 2 is more likely the combustion of fossil fuels, while factor 1 should be other combustion sources instead of burning coal, such as biomass combustion. The generation process is similar to a hybrid process, which includes the graphite oxide-like substances produced by incomplete combustion and the EPFRs formed by some metal oxides. The typical characteristic of factor 3 is that the contribution of metal elements is relatively high, while the contributions of EC and OC are very low. Metal elements such as $\mathrm{Al}, \mathrm{Ti}, \mathrm{Mn}$ and $\mathrm{Co}$ are typical crust elements, so this factor may represent dust sources (Pan et al., 2013; Srivastava et al., 2007; Trapp et al., 2010). The generation mechanism may be mainly due to the participation of metal oxides $n$ the generation of EPFRs. The others are likely derived from the electroplating metallurgy industry (detailed in Sect. S1 in the Supplement). As shown in Fig. 3a2, the contribution ratios of different factors show that the contribution ratios of factor 1 and factor 2 are the highest, and factor 3 only has a small contribution, which indicates that combustion sources, especially incomplete combustion, are the main sources of EPFRs. The particle size distribution characteristics show that factor 1 is mainly distributed in particles larger than $2.1 \mu \mathrm{m}$, while factor 2 is mainly distributed in particles smaller than $0.43 \mu \mathrm{m}$.

The results of the factor analysis in winter are different from those in summer. As shown in Fig. 3b1, the typical spectral characteristic of factor 1 is that it contains a large amount of OC components and As and Se. As and Se are trace elements of coal combustion, as shown in many studies (Pan et al., 2013; Tian et al., 2010), so coal combustion may be the source represented by this factor. From the generation process viewpoint, the factor does not contain EC, but the content of OC is very high. In the particles with a particle size of less than 3.3, which is mainly present in factor 1 , the concentration of OC is 16 times that of EC. So it may be mainly a graphite oxide-like substance formed by the agglomeration of gaseous volatile organic compounds (VOCs) generated during combustion. The typical spectral characteristics of factor 2 are due to a large amount of $\mathrm{V}$ and some $\mathrm{Al}, \mathrm{EC}$ and OC. OC and EC are also typical combustion products. V is rich in fossil fuels, especially fuel oil (Karnae and John, 2011). Therefore, traffic is the source represented by this factor. The factor contains crust elements such as $\mathrm{Al}$ and $\mathrm{Mn}$, so it is speculated that this factor may also include traffic-related dust. The typical spectral characteristics of factor 3 are similar to those of factor 1, and both contain relatively large amounts of As and Se, with the exception that factor 3 contains a large amount of EC, indicating that it is also mainly derived from incomplete combustion sources. The generation process of factor 3 should be different from factor 1, which may include both the graphite oxidelike material generated by fuel coking and the EPFRs generated by the metal oxide. The other factors are mainly atmospheric dust and electroplating or metallurgy (see Sect. S1). As shown in Fig. 3b2, factor 1 and factor 2 have the highest proportions, and factor 3 also has a small contribution, which indicates that winter is the same as summer, and combustion sources are the main source of EPFRs. The particle size distribution characteristics show that factor 1 is mainly distributed in particles with a size of $0.43-3.3 \mu \mathrm{m}$, while factor 2 is mainly distributed in particles larger than $3.3 \mu \mathrm{m}$.

Based on the above analysis, it can be found that combustion sources are the main sources of EPFRs, and EPFRs from these sources are mainly graphite oxide-like substances generated by the polymerization of organic matter or fuel coking. Studies have shown that graphene oxide can cause cell damage by generating ROS (Seabra et al., 2014). The surface of these compounds contains not only carbon atoms but also some heteroatoms, which leads to disorder and the presence of defects in the carbon-based structure (Lyu et al., 2018; Q. Chen et al., 2017; Mukome et al., 2013; Keiluweit et al., 2010). The dust source is also a source of important EPFRs identified in this study (with a contribution of approximately $10 \%$ ). It was shown in the above analysis that the concentration of EPFRs in coarse particles has a significant correlation with the concentration of metallic elements, particularly crustal elements. Some crustal elements, such as $\mathrm{Al}$ and $\mathrm{Fe}$, not only have their own paramagnetism (Li et al., 2017; Yu et al., 2017; Nikitenko et al., 1992), but also interact with aromatic compounds attached to the surface of the particles to produce a stable single-electron structure.

\subsection{Health risk of EPFRs}

To evaluate the health risks of EPFRs in PM with different particle sizes, this study evaluated the comprehensive exposure of EPFRs based on the deposition efficiency of PM with different particle sizes in different parts of the human body. The results are shown in Fig. 4a. The ET region is the region with the highest EPFR exposure, while the TB and P regions have relatively close EPFRs. This result shows that atmospheric EPFRs are the most harmful to the health of the human upper respiratory tract. Comparing the EPFR exposure in different seasons indicates that the exposure risk in the ET area in summer is significantly higher than that in winter. This difference occurs because the concentration of EPFRs in coarse particles is much higher than that of fine particles in summer, and the deposition efficiency of large particles in the ET area is generally higher. Fine particles are more efficiently deposited in the $\mathrm{P}$ region, leading to a higher risk of EPFR exposure in the $\mathrm{P}$ region in winter.

EPFRs were found early in cigarette tar and are considered one of the health risk factors in cigarette smoke (Lyons and Spence, 1960); thus, in this study, the exposure risks of 


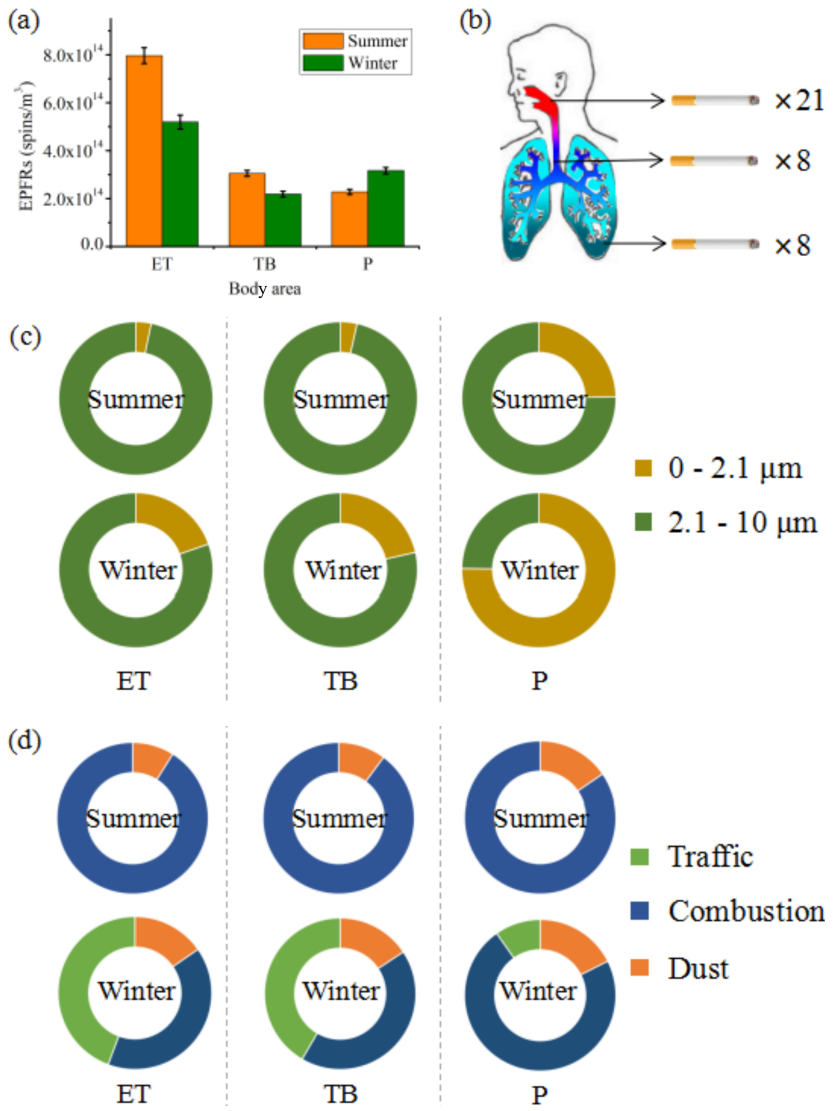

Figure 4. Exposure risks to EPFRs. (a) EPFR exposure in the ET, $\mathrm{TB}$ and $\mathrm{P}$ regions. (b) Cigarette exposure to EPFRs in the human respiratory system. (c) Exposure ratio of EPFRs with different particle sizes in different areas of the respiratory system. (d) Contribution of EPFRs from different sources to different areas of the respiratory system.

EPFRs in particles deposited in the human body were converted to the equivalent number of cigarettes inhaled per adult per day. As shown in Fig. 4b, the ET area is the most contaminated area, with an average equivalence of 21 cigarettes ( 25 in summer and 16 in winter). The average values for the TB area ( 9 in summer and 7 in winter) and $P$ area (7 in summer and 10 in winter) are eight. The results indicate that EPFRs pose significant health risks to human lungs in both winter and summer. Other similar studies, such as a study of the average amount of EPFRs in $\mathrm{PM}_{2.5}$ inhaled per person per day in Xi' an in 2017, found values equivalent to approximately 5 cigarettes (Chen et al., 2018a). Gehling and Dellinger (2013) found that EPFR exposure in $\mathrm{PM}_{2.5}$ is equivalent to approximately 0.3 cigarettes per person per day in St. Joaquin County, the location with the worst air pollution in the United States. The average exposure risk of EPFRs in fine particles in the Linfen area (approximately 13 cigarettes) was higher than those in these two studies. However, these previous studies only studied the exposure risk of EPFRs in fine particles. The results of this study indicate that the health risks of EPFRs are significantly increased when the particle size distribution of EPFRs is taken into account. Therefore, it is important to study the source characteristics and generation process of EPFRs with different particle sizes, which will be discussed in detail in the following paragraph.

This study calculated the proportion of EPFRs with different particle sizes in different parts of the respiratory system based on the deposition efficiency of particles with different particle sizes. As shown in Fig. 4c, in the ET region and the TB region, coarse particles are the dominant component in summer and winter. In particular, in summer, the proportion of EPFRs in coarse particles in these two regions exceeds $95 \%$. In the $\mathrm{P}$ region, there are significant differences between summer and winter. The $\mathrm{P}$ region in summer is still dominated by coarse particles, but its proportion is significantly lower than those in the ET and TB regions. In the $\mathrm{P}$ region in winter, fine particles are the dominant component (approximately $70 \%$ ). These distribution characteristics indicate different sources of EPFRs in different regions. As shown in Fig. 4d, in summer, combustion sources are the main source of EPFRs in the respiratory system. In winter, combustion and transportation sources contribute equally in the TB and ET regions, while in the alveoli, combustion sources are the main contributor. The ET region is the area with the highest risk of exposure to EPFRs ( 21 cigarettes). The generation process of these EPFRs is mainly attributable to graphene oxide-like substances. Studies have shown that graphene oxide is cytotoxic (Harmon et al., 2018). In the alveoli, the contribution of combustion sources is significantly increased (especially in winter). These EPFRs are mainly generated by the action of metal oxides and organic substances. Studies have shown that such EPFRs can generate ROS in the lung fluid environment (Khachatryan and Dellinger, 2011).

\section{Conclusions and environmental implications}

This study systematically reported the particle size distribution of EPFRs in atmospheric PM in Linfen, which is one of the most polluted cities in China and is located in a typical coal-burning area. In addition, this study evaluated the comprehensive health risks of EPFRs and reported possible sources and the formation process of atmospheric EPFRs with respect to different particle sizes. The following main conclusions were obtained.

1. This study found that EPFRs are widely present in atmospheric particles of different particle sizes and exhibit significant particle size distribution characteristics. The results of this study demonstrate that the concentrations and types of EPFRs are dependent on particle size and season. This seasonal characteristic of EPFRs is mainly affected by the PM sources; this result also indicates that the potential toxicity caused by EPFRs may also vary with particle size and season. 
2. This study reported the possible source and formation process of atmospheric EPFRs in different particle sizes. The results show that combustion is the most important source of EPFRs $(>70 \%)$ in both winter and summer PM samples in Linfen. The graphite oxide-like process has the highest contribution $(\sim 70 \%)$ and is mainly distributed in particles with a size of $>0.43 \mu \mathrm{m}$. These findings deepen our understanding of the pollution characteristics of atmospheric EPFRs and are useful for controlling EPFR generation in heavily polluted areas.

3. This study assessed the exposure risk of EPFRs in different areas of the respiratory system. The results show that the upper respiratory tract is the area with the highest EPFR exposure. The trachea and alveoli are also exposed to EPFRs, and the risk of exposure is equivalent to that of 8 cigarettes per person per day. Coarse particles are the main source of EPFRs in the upper respiratory tract, while fine particles are mainly involved in the alveoli.

Through this study, the results have shown that there are significant differences in the concentrations and types of EPFRs in particles of different sizes, and these differences are due to the influence of the source and generation process. In the future, assessments of the particle size distribution and the seasonality of EPFRs in atmospheric PM should be considered. Health risks are another focus of this study. It is found that the upper respiratory tract is the key exposure area of EPFRs, and the traffic source is the main source of EPFRs in this area. This finding is significant for a systematic assessment of the health risks of EPFRs. In view of the complexity and diversity of the formation process of EPFRs in actual atmospheric particulates, the relative contributions of EPFRs generated by different processes and their associated health risks should be more comprehensively studied in the future.

Data availability. All data that support the findings of this study are available in this article and its Supplement or from the corresponding author on request.

Supplement. The Supplement contains additional details, including the EPR spectra of samples of different particle sizes, correlations between EPFRs and carbon in particles of different particle sizes, the results and errors of factor analysis, correlation analysis of EPFRs with metallic elements and EPFR exposure in different areas of the human respiratory tract. The supplement related to this article is available online at: https://doi.org/10.5194/acp-20-144072020-supplement.

Author contributions. QC, HS and YLZ designed the experiments. WS and FC performed sample collection and chemical analysis. CT performed sample chemical analysis. QC and HS performed the
EPR analysis and factor analysis. QC, HS and YLZ prepared the paper with contributions from all co-authors.

Competing interests. The authors declare that they have no conflict of interest.

Acknowledgements. This work was supported by the National Natural Science Foundation of China (grant nos. 41761144056, 41877354 and 41703102), the Provincial Natural Science Foundation of Jiangsu (grant no. BK20180040), the Natural Science Foundation of Shaanxi Province, China (2018JM4011) and the fund of Jiangsu Innovation \& Entrepreneurship Team.

Financial support. This work was supported by the National Natural Science Foundation of China (grant nos. 41761144056, 41877354 and 41703102), the Provincial Natural Science Foundation of Jiangsu (grant no. BK20180040), the Natural Science Foundation of Shaanxi Province, China (2018JM4011) and the fund of Jiangsu Innovation \& Entrepreneurship Team.

Review statement. This paper was edited by James Roberts and reviewed by two anonymous referees.

\section{References}

Arangio, A. M., Tong, H., Socorro, J., Pöschl, U., and Shiraiwa, M.: Quantification of environmentally persistent free radicals and reactive oxygen species in atmospheric aerosol particles, Atmos. Chem. Phys., 16, 13105-13119, https://doi.org/10.5194/acp-1613105-2016, 2016.

Baum, S. L., Anderson, I. G. M., Baker, R. R., Murphy, D. M., and Rowlands, C. C.: Electron spin resonance and spin trap investigation of free radicals in cigarette smoke: development of a quantification procedure, Anal. Chim. Acta., 481, 1-13, https://doi.org/10.1016/S0003-2670(03)00078-3, 2003.

Blakley, R. L., Henry, D. D., and Smith, C. J.: Lack of correlation between cigarette mainstream smoke particulate phase radicals and hydroquinone yield, Food. Chem. Toxicol., 39, 401-406, https://doi.org/10.1016/S0278-6915(00)00144-7, 2001.

Chen, N., Huang, Y., Hou, X., Ai, Z., and Zhang, L.: Photochemistry of hydrochar: Reactive oxygen species generation and sulfadimidine degradation, Environ. Sci. Technol., 51, 1127811287, https://doi.org/10.1021/acs.est.7b02740, 2017.

Chen, Q., Miyazaki, Y., Kawamura, K., Matsumoto, K., Coburn, S., Volkamer, R., Iwamoto, Y., Kagami, S., Deng, Y., and Ogawa, S.: Characterization of chromophoric water-soluble organic matter in urban, forest, and marine aerosols by HR-ToF-AMS analysis and excitation-emission matrix spectroscopy, Environ. Sci. Technol., 50, 10351-10360, https://doi.org/10.1021/acs.est.6b01643, 2016.

Chen, Q., Ikemori, F., Nakamura Y., Vodicka, P., Kawamura, K., and Mochida, M.: Structural and light-absorption characteristics of complex water-insoluble organic mixtures in ur- 
ban submicron aerosols, Environ. Sci. Technol., 51, 8293-8303, https://doi.org/10.1021/acs.est.7b01630, 2017.

Chen, Q., Wang, M., Sun, H., Wang, X., Wang, Y., Li, Y., Zhang, L., and $\mathrm{Mu}, \mathrm{Z}$.: Enhanced health risks from exposure to environmentally persistent free radicals and the oxidative stress of $\mathrm{PM}_{2.5}$ from asian dust storms in erenhot, Zhangbei and Jinan, China, Environ. Int., 123, 260-268, https://doi.org/10.1016/j.envint.2018.09.012, 2018 b.

Chen, Q., Sun, H., Wang, M., Mu, Z., Wang, Y., Li, Y., Wang, Y., Zhang, L., and Zhang, Z.: Dominant fraction of EPFRs from Nonsolvent-Extractable organic matter in fine particulates over Xi'an, China, Environ. Sci. Technol., 52, 9646-9655, https://doi.org/10.1021/acs.est.8b01980, 2018a.

Chen, Q., Mu, Z., Song, W., Wang, Y., Yang, Z., Zhang, L., and Zhang, Y.: Size-Resolved Characterization of the Chromophores in Atmospheric Particulate Matter From a Typical Coal-Burning City in China, J. Geophys. Res.-Atmos., 124, 10546-10563, https://doi.org/10.1029/2019JD031149, 2019a.

Chen, Q., Sun, H., Mu, Z., Wang, Y., Li, Y., Zhang, L., Wang, M., and Zhang, Z.: Characteristics of environmentally persistent free radicals in $\mathrm{PM}_{2.5}$ : Concentrations, species and sources in Xi'an, Northwestern China, Environ. Pollut., 247, 18-26, https://doi.org/10.1016/j.envpol.2019.01.015, $2019 \mathrm{~b}$.

Chen, Q., Wang, M., Wang, Y., Zhang, L., Xue, J., Sun, H., and $\mathrm{Mu}, \mathrm{Z}$.: Rapid determination of environmentally persistent free radicals (EPFRs) in atmospheric particles with a quartz sheet-based approach using electron paramagnetic resonance (EPR) spectroscopy, Atmos. Environ., 184, 140-145, https://doi.org/10.1016/j.atmosenv.2018.04.046, 2018c.

Chen, Q., Sun, H., Wang, J., Shan, M., Xue, J., Yang, X., Deng, M., Wang, Y., and Zhang, L.: Long-life type - The dominant fraction of EPFRs in combustion sources and ambient fine particles in Xi'an, Atmos. Environ., 219, 117059, https://doi.org/10.1016/j.atmosenv.2019.117059, 2019c.

Chen, Q., Sun, H., Wang, M., Wang, Y., Zhang, L., and Han, Y.: Environmentally persistent free radical (EPFR) formation by visible-light illumination of the organic matter in atmospheric particles, Environ. Sci. Technol., 53, 10053-10061, https://doi.org/10.1021/acs.est.9b02327, 2019d.

Chen, Q., Wang, M., Wang, Y., Zhang, L., Li, Y., and Han, Y.: Oxidative potential of water-soluble matter associated with chromophoric substances in $\mathrm{PM}_{2.5}$ over Xi'an, China, Environ. Sci. Technol., 53, 10053-10061, https://doi.org/10.1021/acs.est.9b01976, 2019e.

Cheng, Y., He, K. B., Du, Z. Y., Engling, G., Liu, J. M., Ma, Y. L., Zheng, M., and Weber, R. J.: The characteristics of brown carbon aerosol during winter in Beijing, Atmos. Environ., 127, 355-364, https://doi.org/10.1016/j.atmosenv.2015.12.035, 2016.

Cruz, A. L. N. D., Cook, R. L., Lomnicki, S. M., and Dellinger, B.: Effect of low temperature thermal treatment on soils contaminated with pentachlorophenol and environmentally persistent free radicals, Environ. Sci. Technol., 46, 5971-5978, https://doi.org/10.1021/es300362k, 2012.

D’Arienzo, M., Gamba, L., Morazzoni, F., Cosention, U., Creco, C., Lasagni, M., Pitea, D., Moro, G., Cepek, C., Butera, V., Sicilia, E., Russo, N., Muñoz-García, A., and Pavone, M.: Experimental and theoretical investigation on the catalytic generation of environmentally persistent free radi- cals from benzene, J. Phys. Chem. A., 121, 9381-9393, https://doi.org/10.1021/acs.jpcc.7b01449, 2017.

Dellinger, B., Pryor, W. A., Cueto, R., Squadrito, G. L., Hegde, V., and Deutsch, W. A.: Role of free radicals in the toxicity of airborne fine particulate matter, Chem. Res. Toxicol., 14, 13711377, https://doi.org/10.1021/tx010050x, 2001.

Environmental Protection Agency, Cincinnati, and OH (USA): Recommendations for and documentation of biological values for use in risk assessment, Ntis, PB-179874, EPA 600/6-87/008, 5195594, 1988.

Finkelstein, E., Rosen, G. M., and Rauckman, E. J.: Production of hydroxyl radical by decomposition of superoxide spin-trapped adducts, Mol. Pharmacol., 21, 262-265, 1982.

Gehling, W. and Dellinger, B.: Environmentally persistent free radicals and their lifetimes in $\mathrm{PM}_{2.5}$, Environ. Sci. Technol., 47, 8172-8178, https://doi.org/10.1021/es401767m, 2013.

Han, Y., Chen, Y. J., Saud, A., Feng, Y. L., Zhang, F., Song, W. H., Cao, F., Zhang, Y., Yang, X., Li, J., and Zhang, G.: High time- and size-resolved measurements of PM and chemical composition from coal combustion: Implications for the EC formation process, Environ. Sci. Technol., 52, 6676-6685, https://doi.org/10.1021/acs.est.7b05786, 2018.

Harmon, A. C., Hebert, V. Y., Cormier, S. A., Subramanian, B., Reed, J. R., Backes, W. L., and Dugas, T. R.: Particulate matter containing environmentally persistent free radicals induces AhRdependent cytokine and reactive oxygen species production in human bronchial epithelial cells, Plos One, 13, e0205412, https://doi.org/10.1371/journal.pone.0205412, 2018.

Karnae, S. and John, K.: Source apportionment of fine particulate matter measured in an industrialized coastal urban area of South Texas, Atmos. Environ., 45, 3769-3776, https://doi.org/10.1016/j.atmosenv.2011.04.040, 2011.

Keiluweit, M., Nico, P. S., Johnson, M. G., and Kleber, M.: Dynamic molecular structure of plant biomass-derived black carbon (biochar), Environ. Sci. Technol., 44, 1247-1253, https://doi.org/10.1021/es9031419, 2010.

Khachatryan, L. and Dellinger, B.: Environmentally persistent free radicals (EPFRs)-2. Are free hydroxyl radicals generated in aqueous solutions?, Environ. Sci. Technol., 45, 9232-9239, https://doi.org/10.1021/es201702q, 2011.

Li, G. L., Wu, S. Y., Kuang, M. Q., Hu, X. F., and $\mathrm{Xu}, \mathrm{Y}$. Q.: Studies on the g-factors of the copper(II)oxygen compounds, J. Struct. Chem., 58, 700-705, https://doi.org/10.1134/S0022476617040084, 2017.

Lin, P., Hu, M., Deng, Z., Slanina, J., Han, S., Kondo, Y., Takegawa, N., Miyazaki, Y., Zhao, Y., and Sugimoto, N.: Seasonal and diurnal variations of organic carbon in $\mathrm{PM}_{2.5}$ in Beijing and the estimation of secondary organic carbon, J. Geophys. Res.-Atmos., 114, 1-41, https://doi.org/10.1029/2008JD010902, 2009.

Liu, J., Bergin, M., Guo, H., King, L., Kotra, N., Edgerton, E., and Weber, R. J.: Size-resolved measurements of brown carbon in water and methanol extracts and estimates of their contribution to ambient fine-particle light absorption, Atmos. Chem. Phys., 13, 12389-12404, https://doi.org/10.5194/acp-13-123892013, 2013.

Lyons, M. J. and Spence, J. B.: Environmental free radicals, Br. J. Canc., 14, 703-708, https://doi.org/10.1038/bjc.1960.79, 1960.

Lyu, L., Yu, G., Zhang, L., Hu, C., and Sun, Y.: 4Phenoxyphenolfunctionalized reduced graphene oxide 
nanosheets: A metal-free fenton-like catalyst for pollutant destruction, Environ. Sci. Technol., 52, 747-756, https://doi.org/10.1021/acs.est.7b04865, 2018.

Mihara, T. and Michihiro, M.: Characterization of solventextractable organics in urban aerosols based on mass spectrum analysis and hygroscopic growth measurement, Environ. Sci. Technol., 45, 9168-9174, https://doi.org/10.1021/es201271w, 2011.

Mukome, F. N. D., Zhang, X., Silva, L. C. R., Six, J., and Parikh, S. J.: Use of Chemical and physical characteristics to investigate trends in biochar feedstocks, J. Agric. Food Chem., 61, 21962204, https://doi.org/10.1021/jf3049142, 2013.

Nikitenko, V. A.: Luminescence and EPR of zinc oxide (review), J. Appl. Spectrosc., 57, 783-798, https://doi.org/10.1007/BF00663923, 1992.

Oyana, T. J., Lomnicki, S. M., Guo, C., and Cormier, S. A.: A scalable field study protocol and rationale for passive ambient air sampling: a spatial phytosampling for leaf data collection, Environ. Sci. Technol., 51, 10663-10673, https://doi.org/10.1021/acs.est.7b03643, 2017.

Pan, Y., Wang, Y., Sun, Y., Tian, S., and Cheng, M.: Size-resolved aerosol trace elements at a rural mountainous site in Northern China: importance of regional transport, Sci. Total Environ., 461-462, 761-771, https://doi.org/10.1016/j.scitotenv.2013.04.065, 2013.

Patterson, M. C., Keilbart, N. D., Kiruri, L. W., Thibodeaux, C. A., Lomnicki, S., Kurtz, R. L., Poliakoff, E. D., Dellinger, B., and Sprunger, P. T.: EPFR formation from phenol adsorption on $\mathrm{Al}_{2} \mathrm{O}_{3}$ and $\mathrm{TiO}_{2}$ : EPR and EELS studies, Chem. Phys., 422, 277-282, https://doi.org/10.1016/j.chemphys.2012.12.003, 2013.

Pryor, W. A.: Oxy-Radicals and Related Species: Their Formation, Lifetimes, and Reactions, Annu. Rev. Physiol., 48, 657-667, https://doi.org/10.1146/annurev.ph.48.030186.003301, 1986.

Pryor, W. A., Prier, D. G., and Church, D. F.: Electronspin resonance study of mainstream and sidestream cigarette smoke: nature of the free radicals in gas-phase smoke and in cigarette tar, Environ. Health Perspect., 47, 345-355, https://doi.org/10.1289/ehp.8347345, 1983.

Qi, L., Zhang, Y., Ma, Y., Chen, M., Ge, X., Ma, Y., Zheng, J., Wang, Z., and Li, S.: Source identification of trace elements in the atmosphere during the second Asian Youth Games in Nanjing, China: Influence of control measures on air quality, Atmos. Pollut. Res., 7, 547-556, https://doi.org/10.1016/j.apr.2016.01.003, 2016.

Salma, I., Balásházy, I., Winkler-Heil, R., Hofmann, W., and Záray, G.: Effect of particle mass size distribution on the deposition of aerosols in the human respiratory tract, J. Aerosol. Sci., 33, 119132, https://doi.org/10.1016/S0021-8502(01)00154-9, 2002.

Seabra, A. B., Paula, A. J., Lima, R. D., Alves, O. L., and Durán, N.: Nanotoxicity of graphene and graphene oxide, Chem. Res. Toxicol., 27, 159-168, https://doi.org/10.1021/tx400385x, 2014.

Shaltout, A. A., Boman, J., Shehadeh, Z. F., Al-Malawi, D. A. R., Hemeda, O. M., and Morsy, M. M.: Spectroscopic investigation of $\mathrm{PM}_{2.5}$, collected at industrial, residential and traffic sites in taif, Saudi Arabia, J. Aerosol. Sci., 79, 97-108, https://doi.org/10.1016/j.jaerosci.2014.09.004, 2015.

Song, W., Cao, F., Lin, Y., Haque, M. M., Wu, X., Zhang, Y., Zhang, C., Xie, F., and Zhang, Y.: Extremely high abundance of poly- cyclic aromatic hydrocarbons in aerosols from a typical coalcombustion rural site in China: Size distribution, source identification and cancer risk assessment, Atmos. Res., 248, 105192, https://doi.org/10.1016/j.atmosres.2020.105192, 2020.

Srivastava, A. and Jain, V. K.: Size distribution and source identification of total suspended particulate matter and associated heavy metals in the urban atmosphere of Delhi, Chemosphere, 68, 579589, https://doi.org/10.1016/j.chemosphere.2006.12.046, 2007.

Strak, M., Janssen, N. A. H., Godri, K. J., Gosens, I., Mudway, I. S., Cassee, F. R., Lebret, E., Kelly F. J., Harrison, R. M., Brunekreef, B., Steenhof, M., and Hoek, G.: Respiratory health effects of airborne particulate matter: The role of particle size, composition, and oxidative potential-the RAPTES project, Eviron. Health. Persp., 120, 1183-1189, https://doi.org/10.1289/ehp.1104389, 2012.

Thevenot, P. T., Saravia, J., Jin, N., Giaimo, J. D., Chustz, R. E., Mahne, S., Kelley, M. A., Hebert, V. Y., Dellinger, B., Dugas, T. R., Demayo, F. G., and Cormier, S. A.: Radical-containing ultrafine particulate matter initiates epithelial-to-mesenchymal transitions in airway epithelial cells, Am. J. Respir. Cell. Mol. Biol., 48, 188-197, https://doi.org/10.1165/rcmb.2012-0052OC, 2013.

Tian, H. Z., Wang, Y., Xue, Z. G., Cheng, K., Qu, Y. P., Chai, F. H., and Hao, J. M.: Trend and characteristics of atmospheric emissions of $\mathrm{Hg}$, As, and Se from coal combustion in China, 1980-2007, Atmos. Chem. Phys., 10, 11905-11919, https://doi.org/10.5194/acp-10-11905-2010, 2010.

Tong, H., Lakey, P. S. J., Arangio, A. M., Socorro, J., Shen, F., Lucas, K., Brune, W. H., Pöschl, U., and Shiraiwa, M.: Reactive oxygen species formed by secondary organic aerosols in water and surrogate lung fluid, Environ. Sci. Technol., 52, 11642 11651, https://doi.org/10.1021/acs.est.8b03695, 2018.

Trapp, J. M., Millero, F. J., and Prospero, J. M.: Temporal variability of the elemental composition of African dust measured in trade wind aerosols at Barbados and Miami, Mar. Chem., 120, 71-82, https://doi.org/10.1016/j.marchem.2008.10.004, 2010.

Truong, H., Lomnicki, S., and Dellinger, B.: Potential for misidentification of environmentally persistent free radicals as molecular pollutants in particulate matter, Environ. Sci. Technol., 44, 19331939, https://doi.org/10.1021/es902648t, 2010.

Valavanidis, A. and Haralambous, E.: A comparative study by electron paramagnetic resonance of free radical species in the mainstream and sidestream smoke of cigarettes with conventional acetate filters and bio-filters, Redox. Rep., 6, 161-171, https://doi.org/10.1179/135100001101536274, 2001.

Valavanidis, A., Fiotakis, K., and Vlachogianni, T.: Airborne particulate matterand human health: toxicological assessment and importance of size and composition of particles for oxidative damage and carcinogenic mechanisms, J. Environ. Sci. Heal. C., 26, 339-362, https://doi.org/10.1080/10590500802494538, 2008.

Vejerano, E., Lomnicki, S., and Dellinger, B.: Formation and stabilization of combustion-generated environmentally persistent free radicals on an $\mathrm{Fe}(\mathrm{III})_{2} \mathrm{O}_{3} /$ silica surface, Environ. Sci. Technol., 45, 589-594, https://doi.org/10.1021/es102841s, 2011.

Vejerano, E., Lomnicki, S. M., and Dellinger, B.: Formation and stabilization of combustion-generated, environmentally persistent radicals on $\mathrm{Ni}(\mathrm{II}) \mathrm{O}$ supported on a silica surface, Environ. Sci. Technol., 46, 9406-9411, https://doi.org/10.1021/es301136d, 2012a. 
Vejerano, E., Lomnicki, S., and Dellinger, B.: Lifetime of combustion-generated environmentally persistent free radicals on $\mathrm{Zn}$ (II)O and other transition metal oxides, J. Environ. Monit., 14, 2803-2806, https://doi.org/10.1039/c2em30545c, 2012b.

Vejerano, E. P., Rao, G., Khachatryan, L., Cormier, S. A., and Lomnicki, S.: Environmentally persistent free radicals: Insights on a new class of pollutants, Environ. Sci. Technol., 52, 2468-2481, https://doi.org/10.1021/acs.est.7b04439, 2018.

Wang, P., Pan, B., Li, H., Huang, Y., Dong, X., Fang, A., Liu, L., Wu, M., and Xing, B.: The overlooked occurrence of environmentally persistent free radicals in an area with low-rank coal burning, Xuanwei, China, Environ. Sci. Technol., 52, 10541061, https://doi.org/10.1021/acs.est.7b05453, 2018.

Wang, Y., Li, S., Wang, M., Sun, H., Mu, Z., Zhang, L., Li, Y., and Chen, Q.: Source apportionment of environmentally persistent free radicals (EPFRs) in $\mathrm{PM}_{2.5}$ over Xi'an, China, Sci. Total. Environ., 689, 193-202, https://doi.org/10.1016/j.scitotenv.2019.06.424, 2019.
Yang, L., Liu, G., Zheng, M., Jin, R., Zhu, Q, Zhao, Y., Wu, X., and Yang, X.: Highly elevated levels and particle-size distributions of environmentally persistent free radicals in hazeassociated atmosphere, Environ. Sci. Technol., 51, 7936-7944, https://doi.org/10.1021/acs.est.7b01929, 2017.

Yu, T., Wang, J., Shen, M., and Li, W.: $\mathrm{NH}_{3}-\mathrm{SCR}$ over $\mathrm{Cu} / \mathrm{SAPO}-34$ catalysts with various acid contents and low $\mathrm{Cu}$ loading, Catal. Sci. Technol., 3, 3234-3241, https://doi.org/10.1039/c3cy00453h, 2017. 